\title{
Dynamic Effect in Capillary Pressure- Saturation Relationship and its Impact on Unsaturated Flow
}

\author{
S.M. Hassanizadeh ${ }^{1 *}$, M.A. Celia ${ }^{2}$, and H.K. Dahle ${ }^{3}$ \\ ${ }^{1}$ Section of Hydrology; Faculty of Civil Engineering and Geosciences, Delft University of \\ Technology, P.O. Box 5048, 2600GA Delft, The Netherlands \\ ${ }^{2}$ Environmental Engineering and Water Resources Program, Department of Civil and \\ Environmental Engineering, Princeton University, Princeton, NJ 08544, USA \\ ${ }^{3}$ Department of Mathematics, University of Bergen, \\ Johannes Brunsgate 12, 5008 Bergen, Norway
}

\section{التأثير الديناميكي في علاقة الضغط الشعري بالتشبع وأثره على التدفق غير المشـبع بالمياه}

سيد مجيد حسن زاده ومايكل سيليا وهيلج داهلي

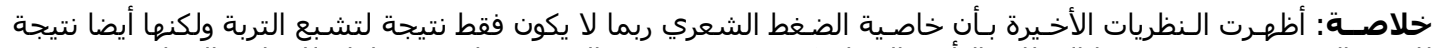

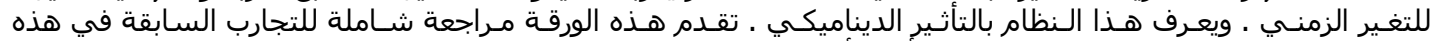

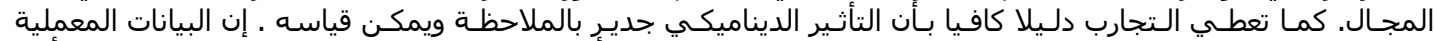

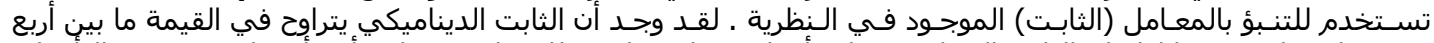

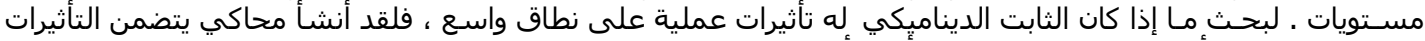

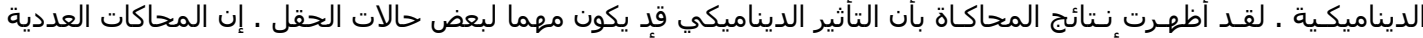

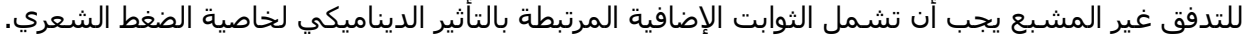

\begin{abstract}
Recent theories indicate that capillary pressure is perhaps not only a function of saturation but also rate of change. This is known as the dynamic effect. A comprehensive review of experiments reported in the literature is presented. The experiments provide ample evidence that a dynamic effect is observable and even quantifiable. The reported data are used to estimate the coefficient that arises in the theory. It was found that range of values of the dynamic coefficients spans about four orders of magnitude. To examine whether these coefficients have any practical effects on larger-scale problems, a continuum-scale simulator was constructed in which the dynamic effects are included. Results of our simulations indicated that the dynamic effect may be important for some field situations. Numerical simulators for unsaturated flow should generally include the additional term(s) associated with dynamic capillary pressure.
\end{abstract}

Keywords: Capillary pressure, saturation, unsaturated flow, dynamic effect, porous media, wetting phase, equilibrium, relative permeability, transient, Darcy's Law.

C apillarity plays a central role in the description of multiphase and unsaturated flow in porous media. In quantitative modelling of multiphase flow, a relationship is needed to describe capillary pressure as a function of other medium properties. Although the underlying processes that determine the distribution of fluid phases in porous media are extremely complicated, the main theoretical and practical tool currently used to quantify

\footnotetext{
*Corresponding author.
} 
the capillary pressure function is an empirical relationship between capillary pressure and saturation in the form (Bear and Verruijt, 1987):

$$
P^{n}-P^{w}=P^{c}=f(S)
$$

where $P^{n}$ and $P^{w}$ are the average pressures of nonwetting and wetting phases, respectively, $P^{c}$ is capillary pressure, and $S$ is the wetting phase saturation.

This simple model is implicitly assumed to account for all effects and processes that influence the equilibrium distribution of fluids, such as surface tension, presence of fluid-fluid interfaces, wettability of solid surfaces, grain size distribution, and microscale heterogeneities. All of these effects are essentially lumped into the $P^{c}-S$ relationship. Moreover, this relationship is obtained experimentally under equilibrium conditions. Thus, to obtain a drainage (or imbibition) curve, one starts with a wet (or dry) soil sample, then the capillary pressure is increased (or decreased) incrementally. At each step the water content is measured after equilibrium is reached. The time to equilibrium after each imposed pressure increment ranges from a few hours to many days, depending on the soil type and saturation degree (Elrick, 1963; Stephens, 1995). The typical time needed to construct a complete capillary pressure-saturation curve is in order of weeks or longer. Now, the question arises whether such curves adequately describe the relationship between $P^{n}$ and $P^{w}$ and $S$ in drainage or imbibition events with a time scale in the order of hours. In fact, there is ample theoretical and experimental evidence that this simple relationship is not unique but it depends on the flow dynamics; it depends on both the history and the rate of change of saturation. The dependence of capillary pressure-saturation curves on the history of flow is known as capillary pressure hysteresis; this is a wellknown effect and has been the subject of extensive investigations. The dependence of capillary curves on the rate of change of saturation is due to dynamic effects; it is much less known and is not quantified properly. The latter effect is the subject of this study.

Another important parameter in the description of unsaturated flow is relative permeability, which is also considered to be a function of saturation. There are some indications that the relative permeabilitysaturation relationship also shows hysteresis effects and may depend on the rate of change of saturation. These effects, however, are less pronounced than in the case of capillary pressure. It must be noted that the dynamic effect considered in this paper is different from the flow-rate dependence of the relative permeability coefficient. It is known that relative permeability shows some dependence on capillary number (basically on the rate of fluid flow). This dependence is more significant at high capillary numbers and is present under steadystate conditions as well (Ramakrishnan and Wasan, 1986). However, the dynamic effect, related to the rate of change of saturation, is a transient effect that may be significant even for small capillary numbers, and is not present under steady-state flow, as discussed later. We assume that Darcy's Law holds.

In this work, we present a dynamic capillary pressure-saturation relationship that was obtained in the framework of a macroscopic theory of porous media flow developed by Hassanizadeh and Gray (1990). Thus, Equation (1) is replaced with:

$$
P^{n}-P^{w}=P^{c}-\tau \frac{\partial S}{\partial t}=f(S)-\tau \frac{\partial S}{\partial t}
$$

where $\tau\left[\mathrm{ML}^{-1} \mathrm{~T}^{-1}\right]$ is a material coefficient that is a measure of the dynamic effect.

\section{Experiments}

An overview of experiments reported in the literature provides ample evidence of the significance of dynamic effects. For example, Topp et al. (1967) carried out drainage experiments on a sandy soil. They determined drainage water content- capillary head relationships by the following three methods: (i) static equilibrium, (ii) steady-state flow and (iii) unsteadystate flow. Plots of water content as a function of capillary pressure head are given in Figure 1. Data points from equilibrium and steady-state experiments fall very close to each other. Based on our theory, this result is expected because in both cases the rate of change of saturation is negligibly small $(\partial S / \partial t \approx 0)$ and thus dynamic effects are not present. In the unsteady-state experiments, the (dynamic) capillary pressure is significantly higher than in the case of equilibrium or steady-state runs. Given the fact that in unsteady state experiments, the rate of change of saturation is negative, the results are clearly in line with the prediction of Equation (2) for drainage. In general, the abnormalities in soil characteristic curves observed in various experiments can be explained by the above equation. The magnitude of the new dynamic capillary pressure coefficient is determined from available data. Its value ranges from $10^{4}$ to $10^{8} \mathrm{~kg} / \mathrm{m} . \mathrm{s}$.

Almost all experiments reported in the literature deal with the case of unsaturated flow. Recently, we have carried out laboratory experiments involving two immiscible phases, namely water and TCE. Both drainage and imbibition experiments were carried out under static as well dynamic conditions. The observations are in line with the unsaturated flow experiments mentioned above. 


\section{DYNAMIC EFFECT IN CAPILLARY PRESSURE - SATURATION RELATIONSHIP AND ITS IMPACT ON UNSATURATED FLOW}

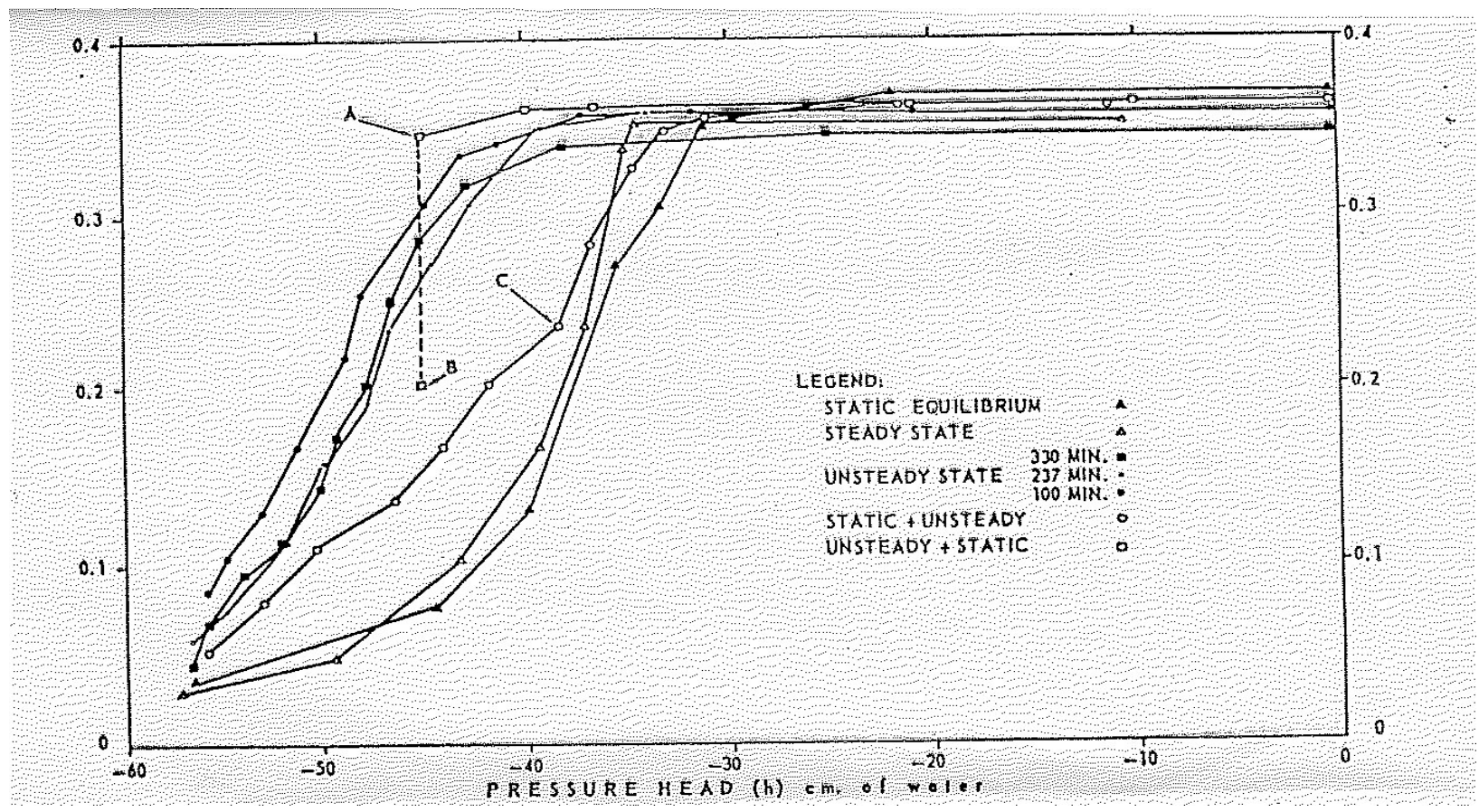

Figure 1. Water content-pressure head data from drainage experiments of Topp et al. (1967).

\section{Numerical Studies}

To examine whether these dynamic effects may be significant in practical situations, a continuumscale simulator was constructed in which Equation (2) is included. This simulator was then run to determine the range of coefficients for which discernable effects occur. Results from such simulations indicate that measured values of dynamic coefficients are within one order of magnitude of those values that produce significant effects in field simulations. This indicates that dynamic effects may be important for some field situations, and numerical simulators for unsaturated flow should generally include the additional term(s) associated with dynamic capillary pressure.

\section{References}

Bear, J. and A. Verruijt. 1987. Modelling Groundwater Flow and Pollution. D. Reidel Publ. Co., Dordrecht, The Netherlands.

Elrick, D.E. 1963. Unsaturated flow properties of soils. Australian J. Soil Res. 1:1-8.

Hassanizadeh, S.M. and W.G. Gray. 1990. Mechanics and thermodynamics of multiphase flow in porous media including interphase boundaries. Adv. Water Resour. 13:169-186.

Ramakrishnan, T.S. and D.T. Wasan. 1986. Effect of capillary number on the relative permeability function for two-phase flow in porous media. Powder Technology 48:99-124.

Stephens, D.B. 1995. Vadose Zone Hydrology. Lewis, Boca Raton.

Topp, G.C., A. Klute, and D.B. Peters. 1967. Comparison of water content-pressure head data obtained by equilibrium, steady-state, and unsteady-state methods. Soil Sci. Soc. Amer. Proc. 31:312-314.

Received September 2002.

Accepted November 2002. 